\title{
The clinical efficacy of ultrasound-guided percutaneous microwave ablation for rib metastases with severe intractable pain: a preliminary clinical study
}

This article was published in the following Dove Press journal: OncoTargets and Therapy

\author{
Zhigang Cheng \\ Xin $\mathrm{Li}$ \\ Chao An \\ Xiaoling Yu \\ Jie Yu \\ Zhiyu Han \\ Fangyi Liu \\ Ping Liang
}

Department of Interventional Ultrasound, Chinese PLA General Hospital, Beijing I00853, People's Republic of China
Correspondence: Ping Liang, MD

Department of Interventional Ultrasound, State Key Laboratory of Kidney Disease, The Chinese PLA General Hospital, No. 28, Fuxing Road, Beijing 100853, People's Republic of China

Tel +86-10-66939530

Fax +86- $10-68161218$

Email liangping30I@I26.com
Purpose: To retrospectively evaluate the clinical efficacy of ultrasound-guided percutaneous microwave ablation (US-PMWA) for patients with rib metastases that caused severe intractable pain.

Materials and methods: From Jan 2016 to Apr 2018, 9 rib metastases from 7 solid tumor patients were treated with US-PMWA. The visual analogue scale (VAS), daily opiate intake doses, local tumor control and complications were recorded and analyzed.

Results: The follow-up period ranged from 6 to 33 months (median: 16 months). The procedures were successfully performed in all of the patients by one ablation. The ablation power ranged from 30 to $60 \mathrm{~W}$, and the ablation time was $610.0 \pm 317.5 \mathrm{~s}$. The mean preablation VAS pain score was $8.1 \pm 0.7$, whereas the mean VAS pain score at $72 \mathrm{~h}$ postablation was $3.3 \pm 0.5(P<0.001)$. All of the patients needed to apply oral and/or intravenous injection opiates to relieve severe intractable pain before ablation, with daily opiate intake doses of $61.4 \pm 30.8 \mathrm{mg}$. After ablation, five patients did not need to apply any opiate treatments $72 \mathrm{~h}$ after ablation, and only two patients needed oral opiates (daily opiate intake doses: $30 \mathrm{mg}$ and $20 \mathrm{mg}$ ). Recurrence was detected in three lesions at 6,11 and 9 months after ablation, with the maximum diameter observed being more than $4 \mathrm{~cm}$. All of the patients were alive during the follow-up period. No minor or major complications occurred. Conclusion: US-PMWA appears to be feasible, convenient, safe and effective in the palliative management of refractory pain caused by rib metastases. This treatment can improve the quality of life of patients and may also achieve promising local control of tumors.

Keywords: microwave ablation, ultrasound-guided, rib metastases, palliative pain

\section{Introduction}

Bone metastases are severe complications in the development of cancer and indicate a worse prognosis. It is the third most common organ site for the development of solid tumors, following liver and lung metastases. ${ }^{1-3}$ Symptoms of bone metastases include localized pain, pathological fractures and functional deficits due to the compression of nervous structures, and these symptoms may limit mobility, as well as decrease the quality of life and overall survival of patients. ${ }^{4,5}$ Localized pain occurs in $90 \%$ of cancer patients, especially patients with advanced stages of cancer. Of these patients, approximately $20 \%$ present with severe intractable pain, which is caused by a direct local invasion or by pressure that arises due to space-occupying 
tumors, microfractures and indirect stretching of the periosteum. ${ }^{6,7}$ The ribs are one of the most common sites of bone metastases. ${ }^{8}$ Rib metastases cause severe intractable pain upon coughing and deep respirations, thus leading to shallow breathing, hypoventilation and the accumulation of secretions, which may cause pneumonia. ${ }^{9}$

Due to the short life expectancies and high systemic tumor burdens of the affected patients with bone metastases, the treatment strategy is usually palliative rather than curative. Therefore, pain palliation has become a priority in these patients. ${ }^{10}$ Conservative approaches have been applied and include the uses of external radiotherapy, chemotherapy and analgesics. ${ }^{2,11}$ Additionally, thermal ablation can not only induce immediate coagulation necrosis of the tumor but also release the compression of the surrounding vessel and nerve, thus achieving optimal pain palliation and local tumor control. ${ }^{12}$ Recently, imaging-guided thermal ablation has been introduced for the treatment of painful bone metastases, with such techniques including CT/MRI/ultrasoundguided percutaneous radiofrequency ablation (RFA), microwave ablation (MWA) and high-intensity focused ultrasound (HIFU). MWA presents certain advantages over the other methods, including higher intratumoral temperatures, faster ablation times, larger possible ablation volumes and less prominent heat-sink effects. ${ }^{13}$ It was reported that CT/MRI-guided MWA has been used in the treatment of bone metastases and has achieved promising local pain palliative effects and tumor control. ${ }^{14-18}$ Ultrasound-guided percutaneous microwave ablation (US-PMWA) has the advantages of being a real-time, convenient, lower-cost and nonradiative treatment and has been widely used for the treatment of many solid tumors in the clinical setting. Additionally, ultrasound diagnoses and therapeutic interventions for bone disease are becoming widely used with increased efficiencies. ${ }^{19}$ The role of US-PMWA in the treatment of rib metastases for the relief of pain has not previously been studied. Thus, this preliminary study was undertaken to determine the safety and efficacy of US-PMWA for the treatment of rib metastases, and specifically for decreasing the intensity and episodes of severe intractable pain arising due to rib metastases. The primary objective of this study was to reduce the intensity of severe intractable pain and to decrease the intake of analgesics. The secondary objectives were to monitor the occurrence of any adverse events and to monitor the local tumor control.

\section{Materials and methods}

\section{Patient selection}

This single-center, preliminary, retrospective study protocol was approved by the Ethics Committee of the Chinese PLA General Hospital (Beijing, China) and was conducted in accordance with the principles of the Declaration of Helsinki. From January 2016 to April 2018, 9 rib metastases from 7 solid tumor patients ( 3 female and 4 male) with a mean age of $61.3 \pm 11.2$ years (range: $50-79$ years) were enrolled. Among the patients, one malignant mesothelioma patient was diagnosed with 3 rib metastases. The mean diameter of the metastases was $3.9 \pm 1.6 \mathrm{~cm}$ (range: 1.5-6.4 cm). The primary tumors consisted of hepatocellular carcinoma (3 cases), malignant mesothelioma (1 case), lung cancer ( 1 case), malignant melanoma ( 1 case) and multiple plasma cell myeloma (1 case).

The inclusion criteria of the study were as follows: 1) patients were verified to have primary malignance tumors via pathological diagnoses; 2) severe intractable pain was measured with at least 4 scores on the visual analogue scale (VAS) with analgesic medications; 3) patients had an Eastern Cooperative Oncology Group performance status (PS) of zero to two; 4) patients had a life expectancy longer than 3 months; 5) patients had prothrombin times $<25 \mathrm{~s}$, prothrombin activities $>40 \%$ and platelet counts $>60$ cells $\times 10^{9} / \mathrm{L}$; and 6 ) patients refused to receive surgical treatments and other treatments. Patients were excluded if they had irreversible cardiopulmonary, renal and liver failure (with medicinal treatments) or any local or systemic infections. Written informed consent was obtained from each of the enrolled patients.

\section{US-PMWA}

The ablations were performed in our institution, and the patients were hospitalized. The microwave system (KY-2000, Kangyou Medical, Nanjing, China) was comprised of an MW generator, a flexible coaxial cable and a cooled-shaft antenna. The 2,450 MHz system was used. The system consisted of three independent MW generators, three flexible coaxial cables and three water-pumping machines, which could drive three 15-gauge cooled-shaft antennae $(0.5 \mathrm{~cm}$ and $1.1 \mathrm{~cm}$ antenna tips $)$ simultaneously. The MW system generators were capable of producing $1-100 \mathrm{~W}$ of power output. The $15 \mathrm{G}$ cooled-shaft antenna was coated with Teflon to prevent adhesion with the dual channels inside of the antenna shaft, through which distilled 
water continuously circulated via a peristaltic pump, which could then cool the shaft to prevent overheating.

The patients were under unconscious intravenous anesthesia (Propofol, 6-12 mg/kg/h; Ketamine, 1-2 mg/kg) during the ablation procedures in the operating room. All treatments were performed by two operators with more than 5 years of ablation experience, according to the operative planning. A US-guided biopsy was performed by using an $18 \mathrm{G}$ cutting needle (C. R. Bard, Japan) before ablation. Afterwards, one or two antennae were implanted in the proper locations. If the tumor was adjacent to the surrounding structures or was superficially close to the skin, hydrodissection techniques were applied for the avoidance of thermal injury, as necessary. The hyperechoic area of ablation was monitored via a grayscale ultrasound, and the endpoints of ablation were decided. The antennae tracks were routinely cauterized to avoid bleeding during withdrawal. After ablation, icing of the ablation area with an ice pack was performed for $24 \mathrm{~h}$ to alleviate the pain and swelling, and antibiotics were routinely administered for three days to reduce inflammation that was caused be thermal damage.

\section{Imaging evaluation and follow-up}

Medical imaging was performed in all of the patients and included computed tomography (CT)/magnetic resonance imaging (MRI), ultrasound, contrast-enhanced ultrasound and emission computed tomography (ECT), both before and after ablation. An ultrasound-guided percutaneous biopsy was performed before ablation and was verified via a pathological diagnosis. VAS was used to assess the pain in each of the patients on a scale from 0 to $10(0=$ no pain, $10=$ the worst pain ever imagined). The therapeutic effect was assessed by contrast-enhanced imaging at 1, 3, 6, and 12 months within the first year and then in 6-month intervals after ablation during the follow-up period. Complete ablation was evaluated by observing enhancements of the contrast-enhanced imaging and a lack of radioactive concentrations on the ECT. The pain intensity scores were evaluated at 24 h, 48 h, 72 h, 1 week, 1 month, 2 months, 3 months and 6 months and were compared with those before ablation. Complications that developed during the intervention and follow-up periods were recorded according to the Society of Interventional Radiology (SIR) criteria. ${ }^{20}$

\section{Statistical analysis}

Data analysis was performed using SPSS 21.0 for Windows (SPSS Inc., Chicago, IL, USA). The continuous data were expressed as the mean \pm standard deviations (SD). The $P$-value was set as 0.05 for statistical significance.

\section{Results \\ Baseline clinicopathological characteristics of the patients, tumors and ablation parameters of the rib metastases}

All of the patient data, tumors and ablation parameters are listed in Table 1. Among the 9 rib metastases, 7 lesions were located in the right rib, and 2 lesions were located in the left rib. For the two lesions that were more than $6 \mathrm{~cm}$, hydrodissection techniques were applied for the protection of the skin. The procedures were successfully performed in all of the patients at one time (Figure 1). The ablation power ranged from 30 to $60 \mathrm{~W}$, and the mean ablation time was $610.0 \pm 317.5 \mathrm{~s}$ (range: $240-1,290 \mathrm{~s}$ ). No minor or major complications occurred, such as skin burn, infections, nerve injury or fracture. The results indicated that US-PMWA exhibited feasibility and safety in the treatment of rib metastases that are resistant to analgesics.

\section{Changes in VAS and treatments before and after ablation}

The mean immediate preablation VAS pain score of all of the treated patients was $8.1 \pm 0.7$ (range: $7-9$ ), whereas the mean $72 \mathrm{~h}$ postablation VAS pain score was $3.3 \pm 0.5$ (range: 1-3). There was a statistically significant decrease in the pain score, compared with the prior pain score, with a $P$-value of $<0.001$. Additionally, the mean VAS pain score at $1 \mathrm{w}$ postablation was $1.9 \pm 0.9$ (range: 1-3), which was significantly decreased compared to preablation score. However, there was a decline at $1 \mathrm{w}$ postablation, compared with the VAS pain score at $72 \mathrm{~h}$, and no statistically significant difference was detected $(P=0.230)$ (Table 2$)$.

Before ablation, all of the patients required an administration of oral and/or intravenous injection of opiates to relieve severe intractable pain. The mean daily opiate dose preablation was $61.4 \pm 30.8 \mathrm{mg}$ (range: $30-120 \mathrm{mg}$ ). After ablation, five patients did not need to apply any treatments $72 \mathrm{~h}$ after ablation, and only two patients required oral opiates. The mean daily opiate intake dose postablation in the two patients were $30 \mathrm{mg}$ and $20 \mathrm{mg}$, compared with $120 \mathrm{mg}$ and $80 \mathrm{mg}$ at preablation (Table 2). No severe intractable pain reoccurred during the follow-up period. 
Table I Characteristics of patients, tumours and ablations parameters of patients with rib metastases

\begin{tabular}{|c|c|c|c|c|c|c|c|c|}
\hline $\begin{array}{l}\text { No/Sex/ } \\
\text { Age }\end{array}$ & $\begin{array}{l}\text { Primary } \\
\text { tumour }\end{array}$ & Location & $\begin{array}{l}\text { Size } \\
(\mathrm{cm})\end{array}$ & $\begin{array}{l}\text { Ablation } \\
\text { energy }\end{array}$ & $\begin{array}{l}\text { Hydrodissection } \\
\text { technique }\end{array}$ & Recurrence & Die & $\begin{array}{l}\text { Follow-up } \\
\text { (m) }\end{array}$ \\
\hline $\mathrm{I} / \mathrm{M} / 52$ & LC & RR5 & 2.9 & $40 \mathrm{~W} \times 420 \mathrm{~s}$ & No & No & No & 8 \\
\hline $2 / M / 62$ & $\mathrm{HCC}$ & RR7 & 1.5 & $30 \mathrm{~W} \times 240 \mathrm{~s}$ & No & No & No & 33 \\
\hline $3 / F / 57$ & $\mathrm{HCC}$ & RR6 & 3.4 & $60 \mathrm{~W} \times 720 \mathrm{~s}$ & No & No & No & 14 \\
\hline 4/F/79 & MMT & $\begin{array}{l}\text { RR3 } \\
\text { RR5 } \\
\text { RR6 }\end{array}$ & $\begin{array}{l}4.5 \\
3.1 \\
3.6\end{array}$ & $\begin{array}{l}60 \mathrm{~W} \times 360 \mathrm{~s} \\
50 \mathrm{~W} \times 360 \mathrm{~s} \\
60 \mathrm{~W} \times 300 \mathrm{~s} \\
60 \mathrm{~W} \times 300 \mathrm{~s} \\
50 \mathrm{~W} \times 240 \mathrm{~s}\end{array}$ & $\begin{array}{l}\text { Yes } \\
\text { No } \\
\text { No }\end{array}$ & Yes & No & 16 \\
\hline $5 / M / 74$ & $\mathrm{HCC}$ & RR5 & 3.7 & $\begin{array}{l}60 \mathrm{~W} \times 300 \mathrm{~s} \\
50 \mathrm{~W} \times 180 \mathrm{~s}\end{array}$ & No & No & No & 18 \\
\hline $6 / M / 50$ & MM & LR6\&7 & 6.2 & $\begin{array}{l}50 \mathrm{~W} \times 600 \mathrm{~s} \\
60 \mathrm{~W} \times 180 \mathrm{~s}\end{array}$ & Yes & Yes & No & 20 \\
\hline $7 / F / 55$ & MPCM & LR5\&6 & 6.4 & $\begin{array}{l}50 \mathrm{~W} \times 690 \mathrm{~s} \\
60 \mathrm{~W} \times 600 \mathrm{~s}\end{array}$ & Yes & Yes & No & 6 \\
\hline
\end{tabular}

Abbreviations: LC, lung adenocarcinoma; HCC, hepatocellular carcinoma; MMT, malignant mesothelioma; MM, malignant melanoma; MPCM, multiple plasma cell myeloma; $\mathrm{RR}$, right rib; LR, left rib; RT, radiotherapy; IV, intravenous injection; W, watt; s, second.

\section{Results of local tumor control and overall survival}

The follow-up period ranged from 6 to 33 months (median: 16 months). Recurrence was detected in three lesions at 6, 11 and 9 months after ablation. The mean diameter of all three of the lesions was more than $4 \mathrm{~cm}$. The results suggested that the larger metastases were risk factors for recurrence. Among the patients, hepatic metastases were detected in one HCC patient, along with poor differentiation, at 10 months after ablation, and this patient then received another ablation. Thus, the pathological diagnoses of primary tumors may be an important risk for overall survival (Table 1).

\section{Discussion}

Percutaneous thermal ablation of bone metastases has only been developed over the past decade. The safety and effectiveness of this treatment for the palliation of painful bone metastases have been demonstrated in some studies. ${ }^{10,21,22}$ Most of the treatments have been performed under CT guidance, which has led to several inconveniences, such as the risk of radioactive exposure to patients and operators. Ultrasound-guided interventional therapies that are portable, have no radioactive exposure risk and have dynamic imaging abilities are an attractive modality in the clinical setting, including for use in spine disease diagnoses and therapeutic interventions. ${ }^{19,23}$ The ribs are superficial and thin structures. The metastases in the ribs can be detected via ultrasound, and a contrast enhanced ultrasound can show the boundaries and relationships of the metastases with the surrounding organs. As illustrated in this primary study, the complete ablation of rib metastases was achieved by use of US-PMWA with one ablation. Additionally, complications related to thermal damage (in the form of skin burns), infections and nerve injury did not occur in this study. These results indicated that US-PMWA is a feasible, safe and efficient approach for the treatment of rib metastases.

The effect of US-PMWA for the relief of severe intractable pain postablation was significant, compared to the pain levels observed before ablation. Most of the patients $(5 / 7)$ did not need to have any treatments applied $72 \mathrm{~h}$ after ablation. Additionally, only two patients required oral opiates, and the mean postablation daily opiate intake dose was significantly reduced. Furthermore, the effect of pain remission was indefinite, as no severe intractable pain was observed to reoccur during the follow-up period. The physiopathological mechanisms of microwave ablation for the relief of pain from rib metastases are as follows. First, microwave ablation may have caused the tumor tissue to undergo coagulation necrosis and possibly even carbonization, which may have reduced the levels of cytokines, inflammatory factors and neurotransmitters expressed by metastases, such as prostaglandins, bradykinin, 5-hydroxytryptamine and $P$ substance. These chemical agents result in the stimulation of sensory nerves, the activation of osteoclast activity, 

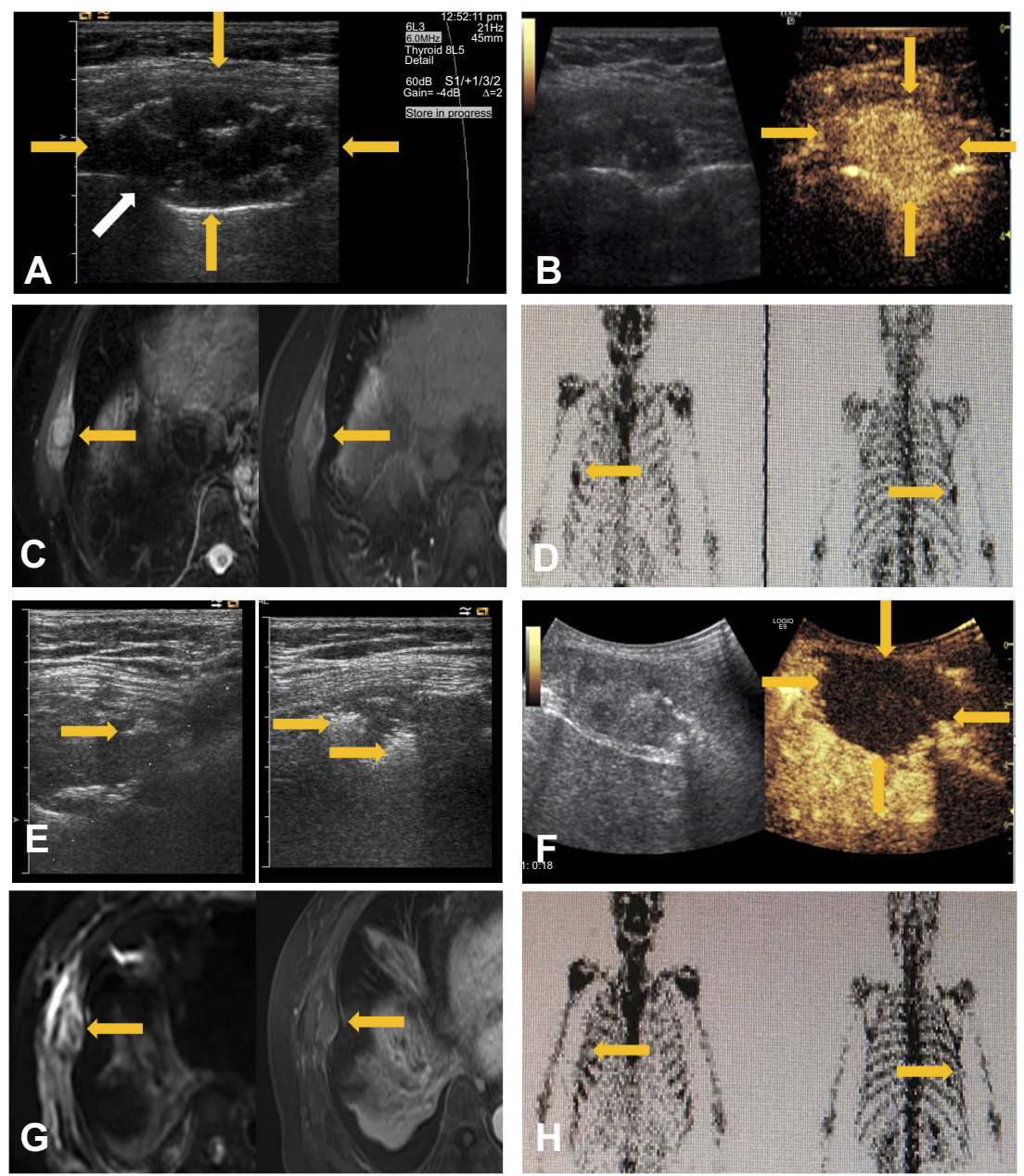

Figure I Images of a 57-year-old-woman who underwent US-PMWA for rib metastases with hepatocellular carcinoma. (A) Preoperative ultrasound imaging showed a hypoechoic lesion, with bone destruction in the right sixth rib (yellow arrow) and periosteal swelling (white arrow). (B, C) The contrast-enhanced ultrasound showed hyperenhancement in the artery phrase, with a size of $3.4 \mathrm{~cm} \times 1.7 \mathrm{~cm}$, and T2-weighted imaging showed a hyperintensity nodule with enhancement in the arterial phase upon MRI imaging (arrow). (D) Before ablation, the lesion showed a radioactive concentration of ECT in the anteroposterior and dorsal positions (arrow). (E) The biopsy was performed by the use of ultrasound-guided techniques, after which two antennae were applied for treatment with US-PMWA with four insertions (arrow). (F, G) No enhancement with complete necrosis was detected from the contrast enhanced ultrasound in the artery, with an ablation zone of $3.9 \mathrm{~cm} \times 2.3 \mathrm{~cm}$, and the T2-weighted imaging showed an inhomogeneous hypo-intensity nodule with no enhancement on the arterial phase upon MR imaging at 3 days after ablation (arrow). (H) No radioactive concentrations were detected upon ECT imaging in the anteroposterior and dorsal positions at 7 days after ablation (arrow). There was no recurrence detected, and severe intractable pain was obviously relieved without the use of analgesic agents during the 14-month follow-up period.

periosteal stretching and pathological fractures, as well as infiltration and the compression of the nerves in the surrounding tissues. ${ }^{24-26}$ Second, microwave ablation may have destroyed not only the tumor itself but also the surrounding tissues, which then resulted in the volume of the metastases being shrunk, thus reducing the tension of the metastases. As a result, the compression to the nerves was released. Third, the intercostal nerve may have been destroyed by ablation of the larger rib metastases, which may have also contributed to the relief of the intensity of pain. As reported by Arif Ahmed in 2015, RF of the intercostal nerves was effective in preventing and decreasing the severity of breakthrough pain arising due to rib metastases. ${ }^{9}$
Based on our results, US-PUMA played a vital role in the relief of severe intractable pain that was caused by rib metastases. Conversely, a promising local tumor control was also achieved during the follow-up period and ranged from 6 to 33 months. In this study, three (3/9) lesions were detected to recur after ablation. After analysis, the recurring lesions had diameters of more than $4 \mathrm{~cm}$, which may be a risk factor for recurrence. The results were similar to those in all of the other malignant tumors after the thermal ablation. Thus, more assistive technology may be needed to achieve a better local tumor control, such as a threedimensional visualization planning system, ${ }^{27}$ because the overall survival of cancer patients is mostly reliant on primary tumor pathological diagnoses. However, there 
Table 2 The changes of treatments and VAS before and after ablation

\begin{tabular}{|c|c|c|c|c|c|}
\hline $\begin{array}{l}\text { No/Sex/ } \\
\text { Age }\end{array}$ & Before ablation & After ablation & $\begin{array}{l}\text { VAS before } \\
\text { ablation }\end{array}$ & $\begin{array}{l}\text { VAS } 72 \mathrm{~h} \text { after } \\
\text { ablation }\end{array}$ & $\begin{array}{l}\text { VAS I w after } \\
\text { ablation }\end{array}$ \\
\hline $\mathrm{I} / \mathrm{M} / 52$ & Oral opiates; $40 \mathrm{mg}$ & No & 8 & 2 & I \\
\hline $2 / M / 62$ & Oral opiates; $30 \mathrm{mg}$ & No & 7 & I & I \\
\hline $3 / F / 57$ & Oral opiates; 60 mg & No & 8 & 3 & 2 \\
\hline $4 / F / 79$ & Oral \& IV opiates; 120 mg & Oral opiates; $30 \mathrm{mg}$ & 9 & 3 & 3 \\
\hline $5 / M / 74$ & Oral opiates; $40 \mathrm{mg}$ & No & 8 & 2 & 1 \\
\hline $6 / M / 50$ & Oral \& IV opiates; $60 \mathrm{mg}$ & No & 8 & 3 & 2 \\
\hline $7 / F / 55$ & Oral \& IV opiates; 80 mg & Oral opiates; $20 \mathrm{mg}$ & 9 & 3 & 3 \\
\hline Average \pm SD & $61.4 \pm 30.8 \mathrm{mg}$ & & $8.1 \pm 0.7$ & $3.3 \pm 0.5$ & $1.9 \pm 0.9$ \\
\hline$p$ & & $0.000 *$ & & $0.000 *$ & $0.000 *$ \\
\hline$p$ & & & & & $0.230^{\#}$ \\
\hline
\end{tabular}

Notes: *The comparsion between before with the $72 \mathrm{~h}$ after ablation; the comparsion between before with the I $\mathrm{w}$ after ablation. ${ }^{\#}$ The comparsion between $72 \mathrm{~h}$ and I $\mathrm{w}$ after ablation.

were only 7 patients enrolled in this study, and the primary tumor pathological diagnoses exhibited heterogeneity, which was the reason why these data were not analyzed in this study. Among the patients, hepatic metastases were detected in one HCC patient with poor differentiation after ablation, and this patient received another ablation.

The limitations of this study were limitations that are inherent to retrospective studies, including small sample sizes and short-term follow-up periods. In addition, the treated lesions were only localized in the ribs and represented superficial lesions that could be easily detected via ultrasound. Therefore, further studies are needed that involve more locations of bone metastases. Third, the palliative pain relief effect and the feasibility and safety of US-PMWA were evaluated in this study, and cement injections may be incorporated in a future study. Lastly, but perhaps most importantly, the standard treatment for a bone metastasis is palliative radiation. Thus, further studies should be performed that examine the comparison between the uses of local ablation and standard radiation treatment.

\section{Conclusion}

In summary, this study demonstrated that US-PMWA appears to be a feasible, convenient, safe and effective treatment for the palliative management of refractory pain in patients with rib metastases. The quality of life of the patients was also improved by a reduction in the daily opiate intake doses. Finally, a promising local tumor control was achieved.

\section{Acknowledgments}

This work was supported by the National Key R\&D Program of China (No. 2017YFC0112000), two grants
(No. 81627803, 91859201, and 81871374) from the National Scientific Foundation Committee of China and a grant (2017FC-CXYY-3005) from the Clinical Research Support Foundation of the Chinese PLA General Hospital.

\section{Disclosure}

The authors report no conflicts of interest in this work.

\section{References}

1. Filippiadis DK, Tutton S, Mazioti A, Kelekis A. Percutaneous image-guided ablation of bone and soft tissue tumours: a review of available techniques and protective measures. Insights Imaging. 2014;5(3):339-346. doi:10.1007/s13244-014-0332-6

2. Johnstone C, Lutz ST. External beam radiotherapy and bone metastases. Ann Palliat Med. 2014;3:114-122. doi:10.3978/j. issn.2224-5820.2014.04.06

3. Smith HS. Painful osseous metastases. Pain Physician. 2011;14: E373-403.

4. Ma Y, Wallace AN, Waqar SN, et al. Percutaneous image-guided ablation in the treatment of osseous metastases from non-small cell lung cancer. Cardiovasc Intervent Radiol. 2018;41:726-733. doi:10.1007/s00270-017-1843-6

5. Berenson JR, Rajdev L, Broder M. Managing bone complications of solid tumors. Cancer Biol Ther. 2006;5:1086-1089. doi:10.4161/ cbt.5.9.3308

6. Portenoy RK, Payne D, Jacobsen P. Breakthrough pain: characteristics and impact in patients with cancer pain. Pain. 1999;81:129-134.

7. Middlemiss T, Laird BJ, Fallon MT. Mechanisms of cancer-induced bone pain. Clin Oncol ( $R$ Coll Radiol). 2011;23:387-392. doi:10.1016/j.clon.2011.03.003

8. Tsuya A, Kurata T, Tamura K, Fukuoka M. Skeletal metastases in non-small cell lung cancer: a retrospective study. Lung Cancer. 2007;57:229-232. doi:10.1016/j.lungcan.2007.03.013

9. Ahmed A, Bhatnagar S, Khurana D, Joshi S, Thulkar S. Ultrasound-guided radiofrequency treatment of intercostal nerves for the prevention of incidental pain arising due to rib metastasis. Am J Hosp Palliat Care. 2017;34:115-124. doi:10.1177/1049 909115617933

10. Kastler A, Alnassan H, Aubry S, Kastler B. Microwave thermal ablation of spinal metastatic bone tumors. J Vasc Interv Radiol. 2014;25:1470-1475. doi:10.1016/j.jvir.2014.06.007 
11. Basile A, Giuliano G, Scuderi V, et al. Cementoplasty in the management of painful extraspinal bone metastases: our experience. Radiol Med. 2008;113:1018-1028. doi:10.1007/ s11547-008-0314-1

12. Tomasian A, Wallace AN, Hillen TJ, Jennings JW. Percutaneous ablation in painful bone tumors. Semin Musculoskelet Radiol. 2016;20:472-485. doi:10.1055/s-0036-1594281

13. Kostrzewa M, Diezler P, Michaely H, et al. Microwave ablation of osteoid osteomas using dynamic MR imaging for early treatment assessment: preliminary experience. J Vasc Interv Radiol. 2014;25:106-111. doi:10.1016/j.jvir.2013.09.009

14. Kastler A, Krainik A, Sakhri L, Mousseau M, Kastler B. Feasibility of real-time intraprocedural temperature control during bone metastasis thermal microwave ablation: a bicentric retrospective study. $J$ Vasc Interv Radiol. 2017;28:366-371. doi:10.1016/j.jvir. 2016.09.030

15. Kurup AN, Morris JM, Callstrom MR. Ablation of musculoskeletal metastases. AJR Am J Roentgenol. 2017;209:713-721. doi:10.2214/ AJR.17.18527

16. Fan QY, Zhou Y, Zhang M, et al. Microwave ablation of malignant extremity bone tumors. Springerplus. 2016;5:1373. doi:10.1186/ s40064-016-3005-8

17. Wei Z, Zhang K, Ye X, et al. Computed tomography-guided percutaneous microwave ablation combined with osteoplasty for palliative treatment of painful extraspinal bone metastases from lung cancer. Skeletal Radiol. 2015;44:1485-1490. doi:10.1007/s00256015-2195-4

18. Botsa E, Mylona S, Koutsogiannis I, Koundouraki A, Thanos L. CT image guided thermal ablation techniques for palliation of painful bone metastases. Ann Palliat Med. 2014;3:47-53. doi:10.3978/j. issn.2224-5820.2014.04.02
19. Ahmed AS, Ramakrishnan R, Ramachandran V, Ramachandran SS, Phan K, Antonsen EL. Ultrasound diagnosis and therapeutic intervention in the spine. J Spine Surg. 2018;4:423-432. doi:10.21037/jss.2018.04.06

20. Callstrom MR, York JD, Gaba RC, et al. Research reporting standards for image-guided ablation of bone and soft tissue tumors. J Vasc Interv Radiol. 2009;20:1527-1540. doi:10.1016/j.jvir.2009.08.009

21. Zhao W, Wang $\mathrm{H}, \mathrm{Hu} \mathrm{JH}$, et al. Palliative pain relief and safety of percutaneous radiofrequency ablation combined with cement injection for bone metastases. Jpn J Clin Oncol. 2018;48:753-759. doi:10.1093/ jjco/hyy090

22. Hu M, Zhi X, Zhang J. Radiofrequency ablation (RFA) for palliative treatment of painful non-small cell lung cancer (NSCLC) rib metastases: experience in 12 patients. Thorac Cancer. 2015;6:761-764. doi:10.1111/1759-7714.12258

23. Obernauer J, Galiano K, Gruber H, et al. Ultrasound-guided versus computed tomography-controlled facet joint injections in the middle and lower cervical spine: a prospective randomized clinical trial. Med Ultrason. 2013;15:10-15.

24. Mantyh PW, Clohisy DR, Koltzenburg M, Hunt SP. Molecular mechanisms of cancer pain. Nat Rev Cancer. 2002;2:201-209. doi: $10.1038 / \mathrm{nrc} 747$

25. Mannion RJ, Woolf CJ. Pain mechanisms and management: a central perspective. Clin J Pain. 2000;16:S144-156.

26. Goblirsch MJ, Zwolak PP, Clohisy DR. Biology of bone cancer pain. Clin Cancer Res. 2006;12:6231s-6235s. doi:10.1158/1078-0432.CCR06-0682

27. Li X, Yu J, Liang P, et al. Combination therapy of three-dimensional (3D) visualisation operative treatment planning system and USguided percutaneous microwave ablation in larger renal cell carcinomas $(\mathrm{D}>/=4 \mathrm{~cm})$ : preliminary results. Int J Hyperthermia. 2016;33 (3): 1-7.doi: 10.1080/02656736.2016.1247299.
OncoTargets and Therapy

\section{Publish your work in this journal}

OncoTargets and Therapy is an international, peer-reviewed, open access journal focusing on the pathological basis of all cancers, potential targets for therapy and treatment protocols employed to improve the management of cancer patients. The journal also focuses on the impact of management programs and new therapeutic agents and protocols on patient perspectives such as quality of life, adherence and satisfaction. The manuscript management system is completely online and includes a very quick and fair peer-review system, which is all easy to use. Visit http://www.dovepress.com/ testimonials.php to read real quotes from published authors. 